\title{
Research on the Process of Al-Mo-Ti Master Alloy Dissolution in Titanium
}

\section{Larionov A.V. ${ }^{1}$, Beltyukov I.A. ${ }^{1}$, Chumarev V.M. ${ }^{1}$, and Vatolin $\mathrm{A}_{0} \mathrm{~N}_{0}{ }^{2}$}

${ }^{1}$ Institute of Metallurgy, Ural Branch of the Russian Academy of Sciences, Ekaterinburg, Russia

${ }^{2}$ Ural Federal University named after the first President of Russia B.N., Yeltsin Ekaterinburg, Russia

\section{Abstract}

This paper presents the results of studying the behavior of the components of the molybdenum-containing Al-(48-52)Mo-(6-9)Ti (wt. \%) master alloy when it is dissolved in liquid titanium. The nature and characteristics of the dissolution of the master alloy in titanium were judged by the results of X-ray microanalysis of the matrix phases (titanium, master alloy) and transition zones (phase boundary). In order to bring the model closer to actual melting conditions, a vacuum arc melting of a titanium sample was used, in which a certain amount of master alloy was encapsulated. The samples

Corresponding Author:

Larionov A.V.

a.v.larionov@ya.ru

Received: 5 February 2019

Accepted: 6 March 2019

Published: 17 March 2019

Publishing services provided by

Knowledge E

(c) Larionov A.V. et al. This article is distributed under the terms of the Creative Commons

Attribution License, which permits unrestricted use and redistribution provided that the original author and source are credited.

Selection and Peer-review under the responsibility of the NIOKR-2018 Conference Committee. were melted around the perimeter so that the liquid titanium only began to interact with the master alloy, after which the melting process was stopped. The obtained results suggest that the composition of the Al-Mo-Ti master alloy is changed by the diffusion transition of molybdenum and aluminum into the titanium melt and counter diffusion of titanium into the master alloy melt. At the same time, a decrease in the concentration of molybdenum in the master alloy is compensated by aluminum and titanium. For every $1.0 \mathrm{wt}$. \% of Al converted into Ti about $2.0 \mathrm{wt}$. \% of Ti dissolves in the master alloy melt. The revealed patterns of changes in the composition of the Al-Mo-Ti master alloy when interacting with liquid titanium suggest that under vacuum-arc melting of titanium alloys the dissolution of the master alloy should not lead to the formation of refractory phases.

Keywords: titanium, molybdenum, aluminum, master alloys, dissolution

\section{Introduction}

Due to its unique physicomechanical properties, titanium and alloys based on it are widely used in various industries [1-6]. The main alloying elements of titanium alloys are aluminum ( $\alpha$-stabilizer) and molybdenum, vanadium ( $\beta$-stabilizers) [6]. To prevent the formation of refractory phases, these elements are introduced into the composition of the pressed electrode for vacuum arc remelting only in the form of master alloys [7-9].

During the ultrasonic testing of titanium alloys billets, sometimes recorded elevated S OPEN ACCESS signals, and at subsequent X-ray control of the templates, they reveal inclusions of 
increased density, which are defects characterized by a high (as compared to titanium) melting temperature and a higher density. The study of the alloy microstructure shows that the defects are melted in and have a transition zone. The central part of the defect, as a rule, is processed with molybdenum. Compared to molybdenum-containing master alloys, which are used in vacuum-arc smelting of titanium alloys, the defects contain less aluminum.

Defects in titanium alloys, found after vacuum arc remelting, are often associated with a high content of refractory phases introduced with master alloys. On the other hand, the cause of the defect formation can be an incomplete melting of the master alloy, which complies with the requirements of the technical specifications, in view of the separation (loss) of the electrode fragment or large particle size of the master alloy, pressed into the electrode. The duration of the alloying additives dissolution is limited by the time during which they are in the liquid metal, i.e. deposited on the surface of the crystallized alloy ingot. Naturally, when entering the alloy crystallization zone, the alloying additions practically no longer dissolve. According to Elyutin V.P. and his co-workers [7] particles of molybdenum, niobium with a particle size of 0.2-1.0 $\mathrm{mm}$ pass through the vacuum arc remelt bath in less than a second. At the same time, the dissolution rate of molybdenum, niobium in titanium, at $1800^{\circ} \mathrm{C}$ at about $0.6 \mathrm{~g} / \mathrm{cm}^{2} \cdot \mathrm{s}$, reduces the mass of particles with a particle size of $0.2 \mathrm{~mm}$ during the movement in the bath by no more than $10.0 \%$.

Despite the fact that the vacuum arc remelting of pressed electrodes is the main industrial process of titanium alloys smelting, the dissolution of alloying elements in the titanium melt has been little studied. This paper presents the results of studying the behavior for the components of the molybdenum-containing master alloy Al-Mo-Ti (AMT) when it is dissolved in liquid titanium.

\section{Materials and Methods of the Experiment}

The interaction of master alloys with titanium during vacuum arc melting of alloys proceeds under conditions of uncontrolled mass exchange. Therefore, the nature and characteristics of the dissolution of the Al-Mo-Ti master alloy in titanium were judged by the results of $\mathrm{X}$-ray microanalysis of matrix phases (titanium, master alloy) and transition zones (phase boundary). In order to bring the model closer to actual melting conditions, a vacuum arc melting of a titanium sample was used, in which a certain amount of master alloy was encapsulated. The chemical composition of the master alloy Al-MoTi is presented in Table 1. According to the data [10], the master alloy is a solid solution of titanium in $\mathrm{Mo}_{3} \mathrm{Al}_{8}$, the melting point $\left(\mathrm{M}_{p}\right)$ is close to $1620^{\circ} \mathrm{C}$. 
Samples of titanium capsuled by master alloy were prepared as follows. Cylinders of $15.0 \mathrm{~mm}$ diameter and $11.0 \mathrm{~mm}$ height were machined from a titanium rod of the grade BT1-00. From the end of the sample, a hole was drilled with the size of $d=9.0 \mathrm{~mm}, \mathrm{~h}$ $=8.0 \mathrm{~mm}$. A piece of master alloy weighing $0.15-0.80 \mathrm{~g}$ was placed in the cavity, then the cavity was caulked with a titanium sponge. A number of samples were prepared by pressing. Titanium crushed material, grade TPP - 3 (according to Russian classification), was poured into the bottom of the mold, then samples of master alloys were placed in the center, and poured with titanium crushed material again. Samples made by such methods were placed in a laboratory vacuum arc furnace 5SA (manufactured by Centorr / Vacuum Industries), equipped with a copper hearth bottom and a non-consumable tungsten electrode. The samples were fused around the perimeter so that the liquid titanium only began to interact with the master alloy, after which the melting process was stopped.

TABLE 1: Composition of the Al-Mo-Ti master alloy.

\begin{tabular}{|l|c|c|c|c|c|}
\multicolumn{7}{c|}{ Composition, wt. \% } \\
\hline Mo & $\mathrm{Ti}$ & $\mathrm{Al}$ & $\mathrm{Cr}$ & $\mathrm{Fe}$ & $\mathrm{Si}$ \\
\hline $48-52$ & $6-9$ & OCт. & 0.3 & 0.6 & 0.5 \\
\hline
\end{tabular}

The fused encapsulated samples were cut in the center of the sinkhole into two parts. At the same time, inside the section, there was a zone into which a piece of the master alloys was caulked into. Further, standard methods were used to prepare thin sections - samples for X-ray microanalysis and metallographic examination. The studies were carried out on a JSM-5900LV scanning electron microscope ( Japan) and an Oxford INCA Energy 200 energy dispersive X-ray spectrometer (United Kingdom).

TABLE 2: The composition of titanium, depending on the distance to the dissolving master alloy AMT (Figure 1a), wt. \%.

\begin{tabular}{|l|c|c|c|c|}
\hline Point & Al & $\mathbf{T i}$ & Mo & $\begin{array}{c}\text { Distance from } \\
\text { master alloy, } \boldsymbol{\mu m}\end{array}$ \\
\hline 1 & 1.04 & 97.77 & 1.19 & 1220 \\
\hline 2 & 1.01 & 97.53 & 1.46 & 1340 \\
\hline 3 & 1.01 & 97.60 & 1.39 & 1360 \\
\hline 4 & 1.15 & 97.10 & 1.75 & 1900 \\
\hline 5 & 0.95 & 97.46 & 1.59 & 2200 \\
\hline 6 & 1.10 & 97.34 & 1.56 & 2780 \\
\hline 7 & 0.97 & 99.03 & 0.00 & 3400 \\
\hline
\end{tabular}



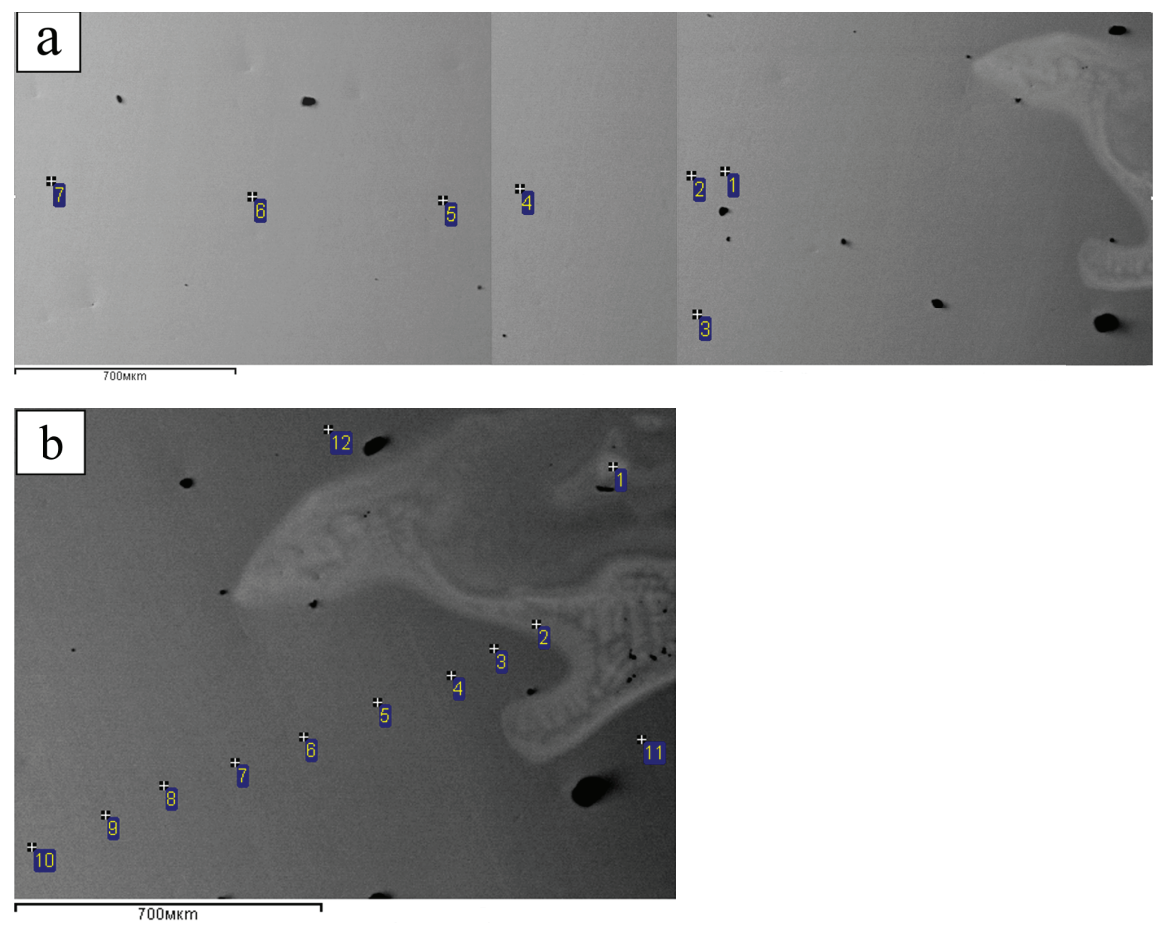

Figure 1: Fragment of the area characterizing the state of AMT master alloy after interaction with liquid titanium with the indication of scanning points.

TABLE 3: Composition of the diffusion zones (Figure 1b), wt. \%.

\begin{tabular}{|l|c|c|c|c|}
\hline Points & $\mathbf{A l}$ & $\mathbf{T i}$ & $\mathbf{M o}$ & \\
\hline 1 & 12.12 & 60.24 & 27.64 & Master alloy change \\
\hline 2 & 15.09 & 66.15 & 18.76 & \\
\hline 3 & 2.81 & 94.81 & 2.38 & 1 zone \\
\hline 4 & 2.12 & 95.69 & 2.19 & \\
\hline 5 & 2.31 & 94.96 & 2.74 & \\
\hline 6 & 1.45 & 96.45 & 2.10 & \\
\hline 7 & 1.06 & 97.46 & 1.48 & 2 zone \\
\hline 8 & 1.14 & 97.46 & 1.39 & \\
\hline 9 & 1.00 & 97.69 & 1.31 & \\
\hline 10 & 0.88 & 97.93 & 1.19 & \\
\hline 11 & 0.00 & 100.00 & 0.00 & To the right of the insert \\
\hline 12 & 1.21 & 97.33 & 1.45 & To the left of the insert \\
\hline & & & & \\
\hline
\end{tabular}

\section{Results and Discussion}

Since the melting point of the AMT master alloy is lower than that of titanium, under the experimental conditions the encapsulated sample of the master alloy melted together 


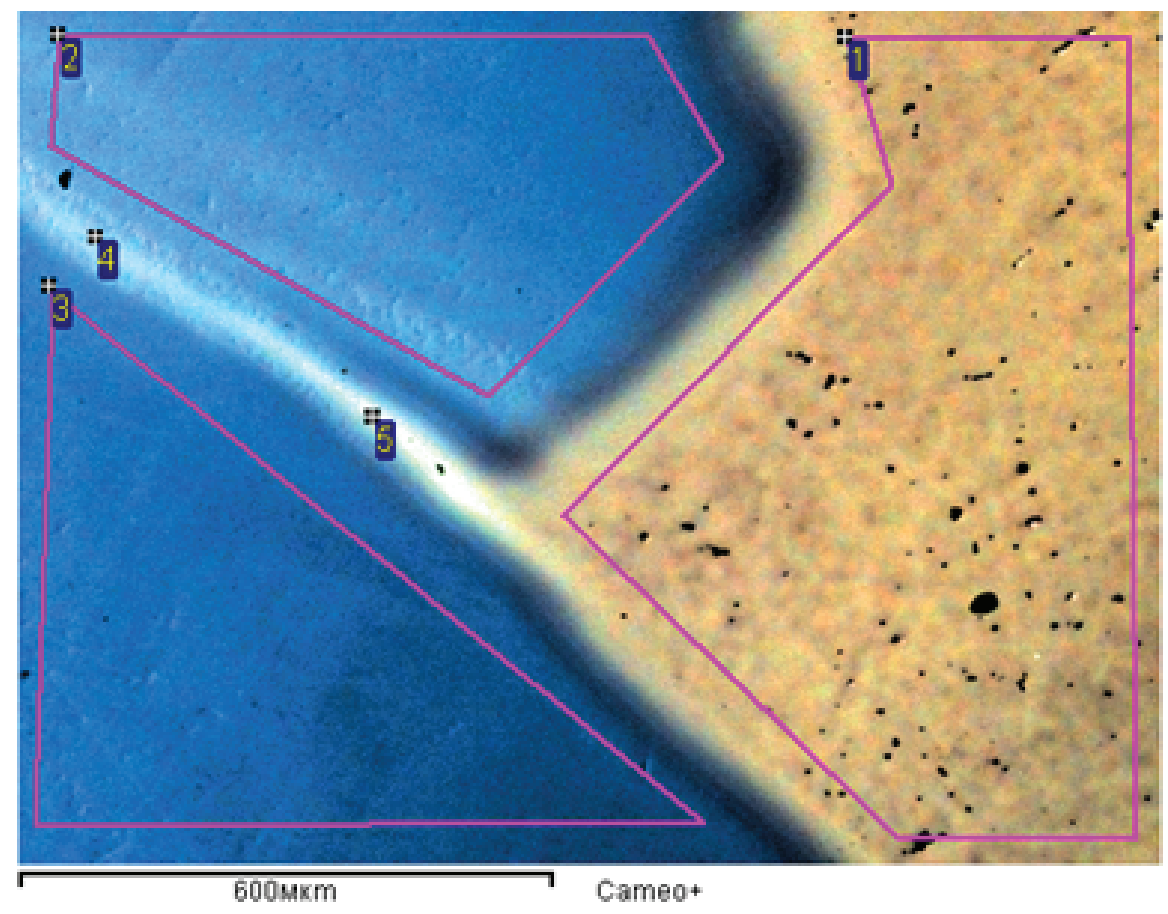

Figure 2: A fragment of the structure, indicating the points for determination of the composition.

TABLE 4: Composition of AMT master alloy and titanium at the scanning points (Figure 2), wt. \%.

Spectrum
1
2
3
4
5

\begin{tabular}{|c|c|c|}
\hline $\mathbf{A l}$ & $\mathbf{S i}$ & $\mathbf{T i}$ \\
\hline 26.38 & 0.26 & 38.12 \\
\hline 2.60 & 0.11 & 93.97 \\
\hline 0.00 & 0.08 & 99.92 \\
\hline 8.60 & 0.12 & 76.57 \\
\hline 13.12 & 0.09 & 56.04 \\
\hline
\end{tabular}

$C r$
0.00
0.00
0.00
0.00
0.13

\begin{tabular}{|c|c|}
\hline Fe & Mo \\
\hline 0.15 & 35.09 \\
\hline 0.00 & 3.32 \\
\hline 0.00 & 0.00 \\
\hline 0.00 & 14.71 \\
\hline 0.14 & 30.47 \\
\hline
\end{tabular}

with titanium - an interaction of two liquid phases occurred. A fragment of an incompletely dissolved master alloy in titanium with dots deposited on it, in which the composition of the matrix phase (titanium) is determined, and the "residue" of the AMT master alloy interacting with it, is shown in Figure 1.

Concentrations of aluminum, molybdenum and titanium were determined by the EPMA method in the diffusion zone of the AMT master alloy dissolution, as well as in

TABLE 5: Changes in the composition of the AMT master alloy during its interaction with titanium.

\begin{tabular}{l|c|c|}
\hline \multicolumn{3}{|c|}{ Composition, wt. \% } \\
\hline Mo & $\mathrm{Ti}$ & $\mathrm{Al}$ \\
\hline $48 \div 50$ & $6 \div 9$ & $41 \div 46$ \\
\hline $36 \div 37$ & $36 \div 38$ & $26 \div 29$ \\
\hline $30 \div 33$ & $39 \div 42$ & $23 \div 27$ \\
\hline $19 \div 27$ & $60 \div 66$ & $12 \div 15$ \\
\hline
\end{tabular}

\begin{tabular}{ccc}
\multicolumn{4}{c}{ Concentration change, $\% \pm$} \\
$\Delta$ Mo & $\Delta \mathrm{Ti}$ & $\Delta \mathrm{Al}$ \\
0 & 0 & 0 \\
-13 & +30 & -16 \\
-18 & +33 & -19 \\
\hline$-(20 \div 24)$ & $+(48 \div 50)$ & $-(27 \div 30)$
\end{tabular}




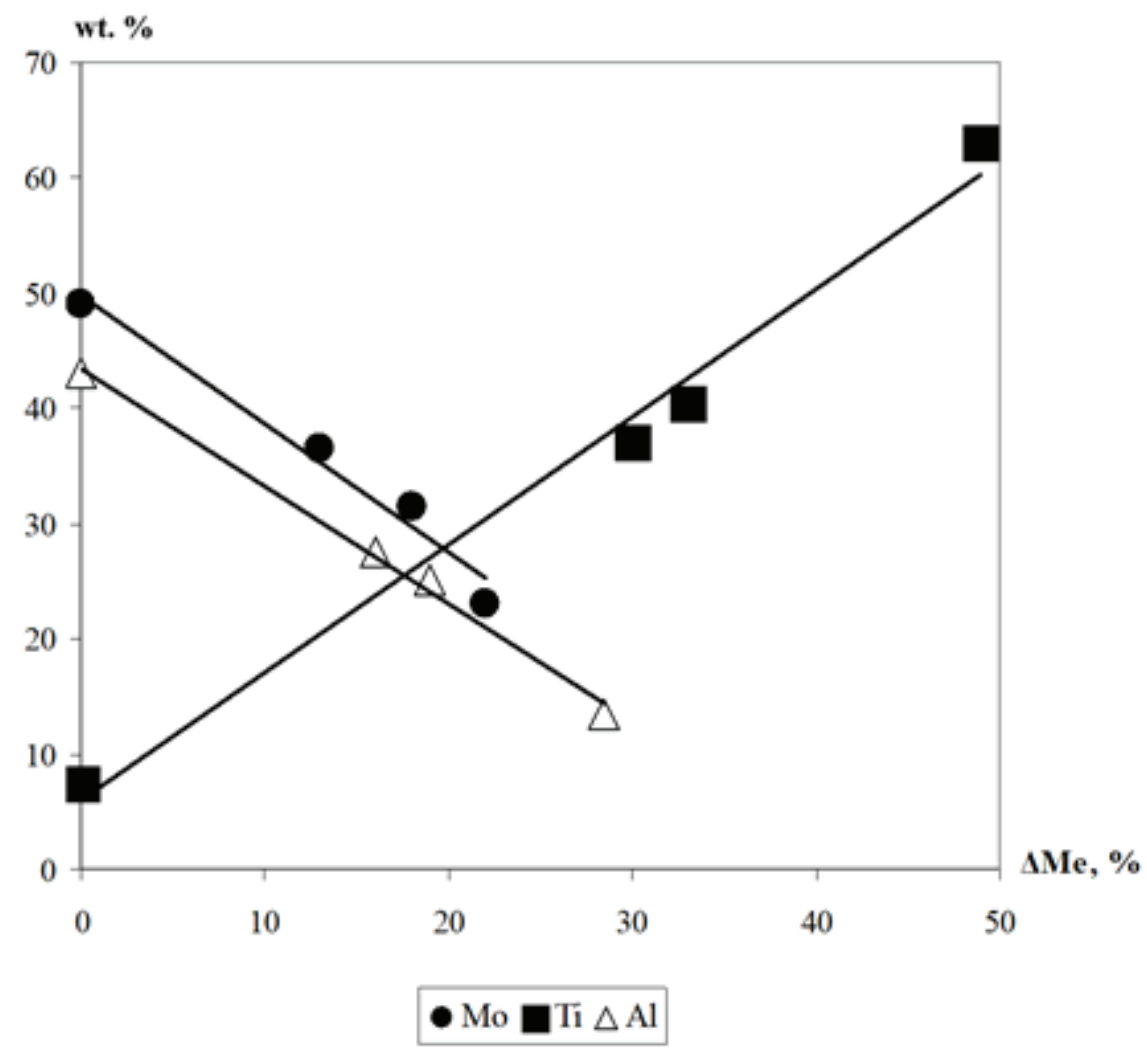

Figure 3: Changes in the composition of AMT master alloy on its dissolution degree in titanium.

titanium at a distance of up to $3400 \mu \mathrm{m}$ from the master alloy. The results of the analysis (Tables 2 and 3) suggest that a change in the composition of the AMT master alloy occurs by the diffusion transition of molybdenum and aluminum into the titanium melt and the counter diffusion of titanium into the melt of the master alloy. At the same time, a decrease in the molybdenum concentration in the AMT master alloy is compensated by aluminum and titanium. For every $1.0 \mathrm{wt}$. \% of aluminum transitioned to titanium in the AMT master alloy melt dissolves about $2.0 \mathrm{wt}$. \% of titanium. Due to this nature of dissolution, there is a change in the composition of the master alloy. Judging by the results of the analysis, under experimental conditions, this led to the fact that at the boundary of the two phases, the composition of the crystallized metal began to correspond to the solid solution of molybdenum in $\mathrm{Ti}_{3} \mathrm{Al}\left(\mathrm{Ti}_{3} \mathrm{Al}+\mathrm{Mo}\right)$. The $\mathrm{M}_{p}$ of an alloy of this composition is $1750-1800{ }^{\circ} \mathrm{C}$, i.e., slightly higher than titanium $\mathrm{M}_{p}$. Under conditions of metal overheating during the vacuum arc melting, this should not lead to crystallization of the refractory new formed structures - products of the AMT master alloy interaction with titanium.

During the experiments, it was also possible to see the earlier stages of the interaction for the AMT master alloy with liquid titanium (Fig. 2, Table 4). From the obtained results, it follows that the interaction of the AMT master alloy with titanium symbiotically reduces 
the concentration of Mo and $\mathrm{Al}$ in it. At the same time, a decrease in their content is compensated by an increase in the titanium concentration.

The relationship of the composition for the dissolving of master alloy in titanium with a change in the concentrations of Mo, Ti and $\mathrm{Al}$ in it is clearly presented in Table. 5 and Fig. 3. From the obtained data, it follows that when the AMT master alloy is dissolved in liquid titanium, no phase should be formed, the melting point of which exceeds 1750 $1800^{\circ} \mathrm{C}$.

From the compositions of the crystallized phases studied by us (in this experiment), the most refractory may be the phase corresponding to the composition of $\mathrm{TiAlMo}_{0.5}$. Its melting point (liquidus) does not exceed the specified limits.

Thus, the revealed patterns of changes in the composition of the AMT master alloy during interaction with titanium allows to suggest that under vacuum arc melting of titanium alloys the dissolution of AMT master alloy should not lead to the formation of phases processed by molybdenum and simultaneously depleted by aluminum.

\section{Conclusions}

When studying the dissolution of the AMT master alloy in titanium, no phases processed by molybdenum and depleted by aluminum were found. The Mo: Ti: Al ratios in the studied samples of the master alloy after co-melting with titanium do not indicate the possibility of the formation for refractory phases.

\section{References}

[1] Zvikker, U. (1979). Titanium and its alloys. Moscow.: Metallurgiya.

[2] Ed. by Boyer, R., G.Welsch, E.W.Colling. (1994). Materials Properties Handbook. Titanium. ASM International. The Material Information Society.

[3] Ed. by Leyens, C., Peters, M. (2003). Titanium and Titanium Alloys. Fundamentals and Application. WILEY-VCH Verlag GmbH \& Co. KGaA, Weinkeim.

[4] Horev, M.A., Horev A.I. (2005). Titanium alloys, their application and development prospects. Materialovedenie, no.7, pp. 25-34.

[5] Ed. by Joshi, V.A. (2006). Titanium Alloys. An Atlas of Structures and Fracture Features. Taylor and Francis Group.

[6] Il'yn, A.A., Kolachev B.A., Pol'kinl.S. (2009). Titanium alloys. Composition, structure, properties. Handbook. Moscow.: VILS - MATI. 
[7] Elyutin, V.P., Pavlov Yu. A. (1972). High temperature materials. Part 1. Physical chemical basics for obtaining of refractory materials. Moscow.: Metallurgiya.

[8] Elyutin, V.P., Kostikov V.I., Lysov B.S. et al. (1973). High - temperature materials. Part 2. Obtaining and physical - chemical properties of high-temperature materials. Moscow: Metallurgiya.

[9] Andreev, A.L., Anoshkin, N.F., Borzecovskaya, K.M. et al. (1978). Titanium alloys. Melting and casting of titanium alloys Moscow.: Metallurgiya.

[10] Chumarev, V.M., Mar'evich, V.P., Chentsov, V.P. et al. (2009). Phase composition and melting points of aluminothermic master alloys for rare refractory metals. Rasplavy, no. 3, pp. 29-35. 